\title{
Implant infections and antibiotic-impregnated silicone rubber coating
}

\author{
D N RUSHTON*, G S BRINDLEY*, C E POLKEY, $\dagger$ G V BROWNING \\ From the Medical Research Council Neurological Prostheses Unit, ${ }^{*}$ the Guy's-Maudsley Neurosurgical Unit ${ }^{\dagger}$ \\ and the Department of Pathology, Maudsley Hospital, $\ddagger$ London UK
}

SUMMARY A method is described for coating silicone rubber-encapsulated implant devices with an outer layer of silicone rubber impregnated with a mixture of gentamicin sulphate and diethanolamine fusidate. A coating of this sort provides bactericidal activity lasting for a few days in the film of fluid surrounding such an implant. When used for coating our implants, the retrospective rate of implant infections believed to have been introduced at the time of surgery was reduced to $0.7 \%$ (coated), compared with $10.0 \%$ (uncoated), a highly significant difference $(\mathrm{p}<0.001)$. Systemic perioperative antibiotic prophylaxis was not shown to confer any such benefit.

Electrical faults and colonisation by micro-organisms are the two major causes of failure of implanted stimulator devices such as neurological prostheses, and the second of these causes of failure is one shared with other silicone rubber implant devices such as hydrocephalus shunts. ${ }^{1-3}$ Electrical failures can generally be repaired without much delay, if the implant is well-designed, but an infected implant must be removed, and it is our experience that a delay of at least 12 months must elapse before it can be replaced without fear of recrudescence of infection. Systemic antibiotic treatment of infection established around an implant is unsuccessful unless the implant is removed, because the potential space between the implant and the surrounding connective tissue or fibrous tissue encapsulation is relatively poorly reached both by systemic antibiotics and by body defences, and allows free spread of bacteria in the fluid film.

Of the first 35 devices designed in the MRC Neurological Prostheses Unit that were implanted into patients (February 1972 to December 1981), two became infected $(5 \cdot 7 \%)$. It seemed likely that the organisms causing colonisation were derived from the patient's skin and implanted at the time of operation, and that they were able to thrive and cause a serious infection because of their privileged position at the implant surface. It appeared that implant infections never occurred later, unless the implant was exposed

Address for reprint requests: Dr DN Rushton, Institute of Psychiatry, De Crespigny Park, London SE5 8AF, UK.

Received 25 January and in revised form 24 March 1988. Accepted 18 August 1988 for some reason; instances where this happened are discussed below.

For some implant types it has been shown ${ }^{46}$ that systemic treatment with prophylactic antibiotics at the time of surgery can reduce the rate of implant infection, provided treatment is effective during a "decisive period" of $0-4 \mathrm{~h}$ after surgery. Systemic treatment requires relatively large doses to attain a bactericidal concentration at the implant surface, with a correspondingly increased risk of resistance, sideeffects and superinfections. These risks are clearly more weighty when an antibiotic is being given prophylactically rather than for an established infection. For some types of implant (notably hip replacements and cardiac pacemakers), systemic prophylaxis has been found to be effective in reducing implant infections by a factor of $3^{56}$ to $7 \cdot 7 ;^{4}$ short courses seem to be as effective as long ones. ${ }^{7}$ For hip replacements, gentamicin-impregnated bone cement has been shown to be significantly better even than a course of systemic antibiotic, ${ }^{8}$ reducing the rate from $1.6 \%$ (systemic antibiotic) to $0.36 \%$ (gentamicinimpregnated bone cement), a further factor of $4 \cdot 4$. For other implants such as hydrocephalus shunts the evidence (based on smaller numbers) is so far inconclusive.' Haematogenous infection of implants is probably rare, except for the case of artificial heart valves. ${ }^{10}$ This is because after the formation of the fibrous tissue capsule around an implant, blood no longer reaches the vulnerable potential space between the implant and fibrous capsule, being separated from it at least by capillary endothelium. For artificial heart valves, perioperative antibiotic prophylaxis is univer- 
sity used (and almost certainly effective), without a formal controlled trial having ever been undertaken. ${ }^{10}$

We therefore considered ways of generating a bactericidal concentration of appropriate antibiotic at the site where it is required (in the potential space between implant and tissues), at the time when it is required (during the first few hours and days after implantation). Spraying with antibiotic powder during surgery may be effective for the parts of the implant that it can reach, but it cannot reach cables or tubes implanted by pulling through a cannula.

We sought a method for antibiotic impregnation of the surface layer of an implant, using agents that could withstand the processes of implant manufacture, storage and autoclaving, and which would diffuse out over a suitable period after implantation. Several methods have been described ${ }^{11}$ for antibiotic impregnation of a heat-crosslinking rubber used in the manufacture of hydrocephalus shunts. Bayston and Milner showed that the method of physical preparation of the antibiotic and its mixing with the rubber was often crucial, that gentamicin sulphate, sodium and diethanolamine fusidates and clindamycin hydrochloride were stable through the manufacturing process for their rubbers, and that when immersed they diffused out with a bactericidal effect lasting for a relatively short (gentamicin) or a relatively prolonged (diethanolamine or sodium fusidate, clindamycin) period of in vitro testing.

Experience of hydrocephalus shunt infections is wide,${ }^{1-3}$ and the commonest organism is there found to be Staphylococcus epidermidis followed by $S$. aureus and diphtheroids, and occasionally Proteus and Pseudomonas species. We are not aware of any published account of infecting organisms in neurostimulator implants, but our infections included the same list of organisms as for shunts, in the same order of frequency. We therefore chose a mixture of antimicrobial agents appropriate to the range of organisms likely to initiate infections. Fusidic acid is a specific antistaphylococcal agent with high activity and stability. Some resistance is known to occur, and this agent is only effective against Gram-positive bacteria, so we also included gentamicin sulphate in the coating. This is a broad-spectrum antibiotic, with high activity against most Gram-negative bacteria including Pseudomonas species. Gentamicin sulphate is highly heat-stable, but does show some loss of activity at low $\mathrm{pH}$. It seemed likely that a coarse particulate form of gentamicin incorporated in the surface of the rubber would be most effective, since it had been shown that only incompletely incarcerated particles would be effective, ${ }^{11}$ whereas for diethanolamine fusidate the particle size mattered less, because the drug could diffuse through silicone rubber.
We chose to impregnate only a surface coating of silicone rubber applied to the implant after manufacture was otherwise complete, rather than the fullthickness method propsed by Bayston and Milner. There were several reasons for this. Firstly, admixing a coarse particulate preparation of antibiotic powder is likely to degrade the physical properties of the rubber, whose mechanical strength and electrical insulating properties are important. ${ }^{12}$ Secondly, different parts of the implant are made in different ways at different times, so coating is simpler. Thirdly, since the diffusion of gentamicin in particular through rubber is so slow, antibiotic particles in the depths of the rubber would be ineffective. Lastly, whereas there is for shunts a need to protect the lumen as well as the outer surface, ${ }^{3}$ for stimulators there is no such need.

\section{Methods in vitro}

We used air-curing adhesive silicone rubbers, described by the manufacturers as ("medical adhesive" (Dow-Corning Type 891), 'adhesive/sealant" (Dow-Corning Type 734) or "coating" (Dow-Corning Type 3140). Heat or pressure are not required for their cure, but they all evolve either acetic acid $(891,734)$ or methanol $(3140)$ in the curing process. It was therefore necesary to make in vitro tests of the antimicrobial effectiveness of implant samples coated with acid- or alcohol-evolving rubbers impregnated with one or both of gentamicin sulphate and diethanolamine fusidate.

Samples of implant cable, consisting of silicone rubber with a number of helically-wound insulated platinum or platinum-iridium conductors embedded in it ("Cooper cable"; see ref 13) were coated with a layer of antibiotic zo impregnated rubber. The manufactured diameter of cables is $1.9 \mathrm{~mm}$, and the thickness of the impregnated coating $0.125 \mathrm{~mm}$, so that the final diameter is $2.15 \mathrm{~mm}$. The impregnated rubber was prepared by mixing with a spatula $20 \mathrm{mg}$ of either or both antibiotics with each 1 gram of liquid rubber, mixing quickly and thoroughly until it appeared uniform, and then applying it to the cable by hand using a split die. ${ }^{24}$ Using this method, particle size for gentamicin sulphate (Nicholas) was about $0.001-0.01 \mathrm{~mm}$, and for diethanolamine fusidate (Leo) about $0.01-0.02 \mathrm{~mm}$. After air-curing the samples were stored for 1 week and then autoclaved in a steam autoclave $\left(135^{\circ} \mathrm{C}\right.$ for $\left.5 \mathrm{mins}\right)$, or else stored for 6 months and then autoclaved, before being tested for antibacterial activity.

Tests for antibacterial activity were carried out on lengths of cable of $1 \mathrm{~cm}$ or longer, placed onto petri dishes of Sensitivity Test agar (Lab M) supplemented with $5 \%$ lysed horse blood (TCS) previously seeded with suspensions of either Stapyhylococcus aureus NCTC 6571 or Escherichia coli NCTC 10418. Turbidity was standardised to a McFarland barium sulphate standard No 1 . Some samples were tested after elution in still physiological saline at $37^{\circ} \mathrm{C}$ for 1,3 and 7 days. Widths of zones of inhibition were measured after incubation for $18 \mathrm{~h}$ at $37^{\circ} \mathrm{C}$. The width of the contact surface was narrower than the cable diameter, so the width recorded was the total width of the zone of inhibition. All samples were tested in duplicate or more, and the zones were measured by 

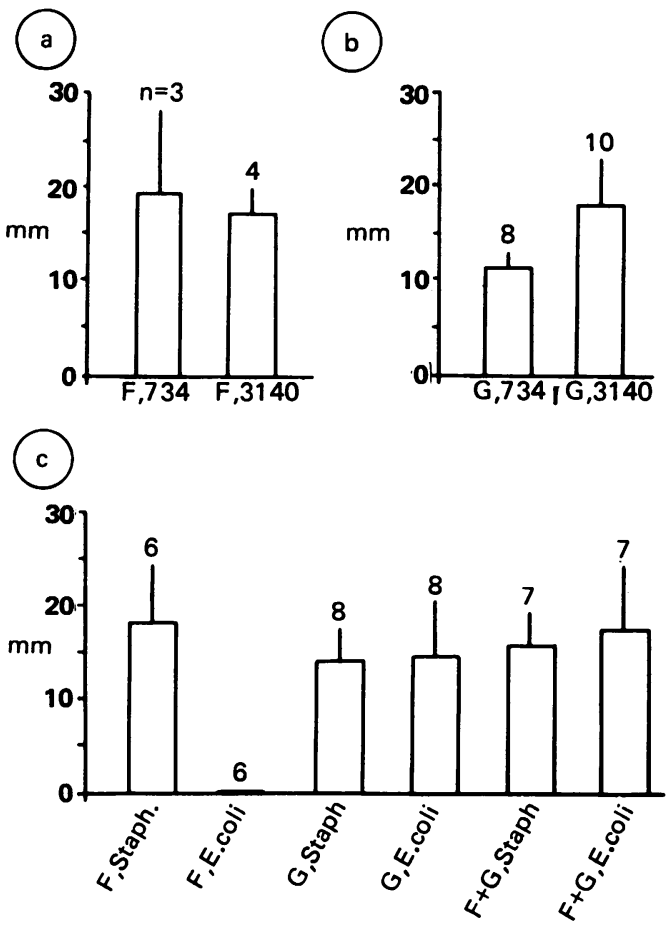

Fig 1 Effect of mixing antibiotics and rubbers. For each condition the mean width of the zone of inhibition after $18 \mathrm{~h}$ incubation is given, together with the $S D$ and the number of samples. (a) Effect of rubber type on antibacterial activity: diethanolamine fusidate $(F)$. "734" is an acetic acid-evolving air-curing adhesive/sealant rubber. "3140" is a methanolevolving air-curing coating rubber. There is no apparent loss of activity in acetic acid-evolving rubber, (b) Effect of rubber type on antibacterial activity: gentamicin $(G)$. There is a small but statistically significant loss of in vitro antibacterial activity (see text), (c) Effect of combining two antibiotics; different rubber results are combined. There is no evident mutual interference between the two antibiotics.

the bacteriologist who was blind to the coating type. Zone widths of less than $2 \mathrm{~mm}$ were counted as zero.

\section{Results in vitro}

Results comparing the use of acid- and alcohol-evolving rubbers are shown in fig la for diethanolamine fusidate (staphylococcus only) and in fig $1 \mathrm{~b}$ for gentamicin (staphylococcus and E coli results combined). It should not be surprising that acid-evolution in curing does not appear to affect the activity of diethanolamine fusidate, which is an ester and would be expected to be hydrolysed by acetic acid; fusidic acid itself is an active antibiotic with enhanced activity at low $\mathrm{pH}$, although it is less soluble than its ester. Gentamicin (fig 1b), although acid-stable, does have reduced antimicrobial activity at low $\mathrm{pH}$. It shows a small loss of activity in acid-evolving rubber which just reaches significance (unpaired $t$ test; $0.01<p<0.05$ ). Figure lc shows the widths of zones of inhibition for the two antibiotics separately and together. There is no evidence of significant mutual interference. Figure $2 \mathrm{a}, \mathrm{b}$ compares the zones of inhibition with and without autoclaving. For both antibiotics there is a slight diminution in activity, and this is not surprising as the water condensate which is formed in steam autoclaving would be expected to leach away some of the most accessible small antibiotic particles. Figure 2c shows the effect of 6 months aging at room temperature in a plastic box on the laboratory shelf, followed by steam autoclaving, compared with non-aged samples. There is no evidence of loss of activity with time alone. This test used alcohol-evolving rubber but there is no reason to expect that acid-evolving rubber would be any different, as all the acetic acid evaporates from a thin coating in a few hours.

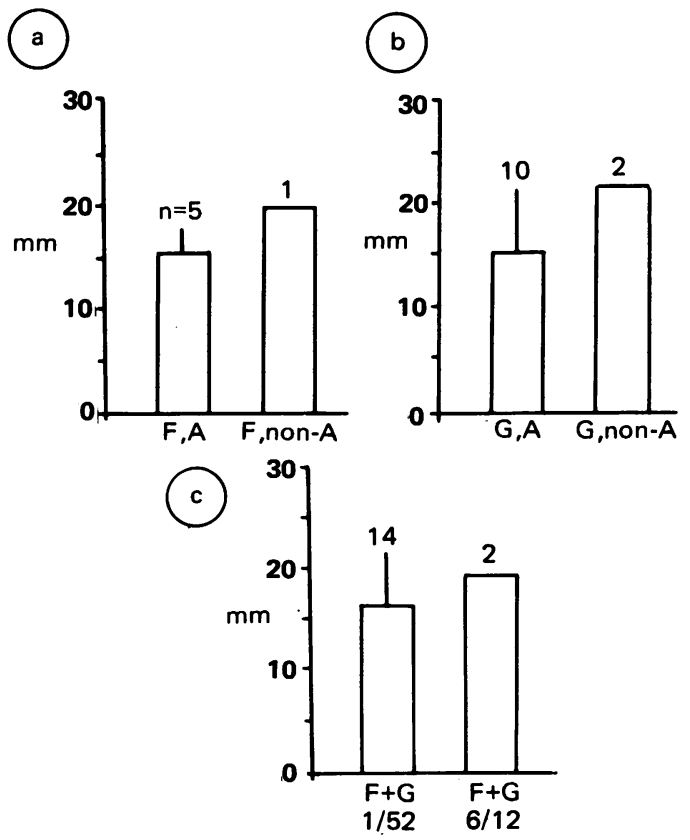

Fig 2 Effect of processing and storage on in vitro antibacterial activity (3140). (a) Effect of autoclaving on diethanolamine fusidate-loaded $(F)$ coating. $A=$ after autoclaving. Non- $A=$ without autoclaving. Steam autoclave, $135 \mathrm{deg} C$ for 5 minutes. (b) Effect of autoclaving on gentamicin-loaded coating. $A=$ after autoclaving. Non$A=$ without autoclaving; (c) Effect of aging on combination-loaded $(F+G)$ rubber. 1/52= tested one week after coating, autoclaved. $6 / 12=$ tested six months after coating, autoclaved. 
Tests for the persistence of antibacterial activity were performed by blotting and plating samples after 1,3 or 7 days of immersion in $20 \mathrm{ml}$ physiological saline in a sample tube, at $37^{\circ} \mathrm{C}$. It was felt that immersion without continuous agitation would most fairly represent the rate of antibiotic leaching that would occur after implantation, as against continuous agitation (too severe) or serial plate transfer (too mild). Results are given in fig 3. It is clear that in agreement with Bayston and Milner, ${ }^{10}$ who used a different method, fusidic acid remains active for much longer than gentamicin, and after the initial rapid decline it may reach a plateau or slow decline; while gentamicin activity is near to zero after 3 days of elution.

\section{Methods in vivo}

From January 1982 we coated most devices, and from January 1983 all devices, for implantation into patients in the Maudsley Hospital with a mixture of $96 \%$ by weight silicone rubber, mixed with $2 \%$ diethanolamine fusidate and $2 \%$ gentamicin, applied as described for Methods in vitro. The total dose contained in each implant so coated is approximately $40 \mathrm{mg}$ of diethanolamine fusidate and $40 \mathrm{mg}$ gentamicin, so at no time after implantation could there be a therapeutic systemic antibiotic level. All implants were

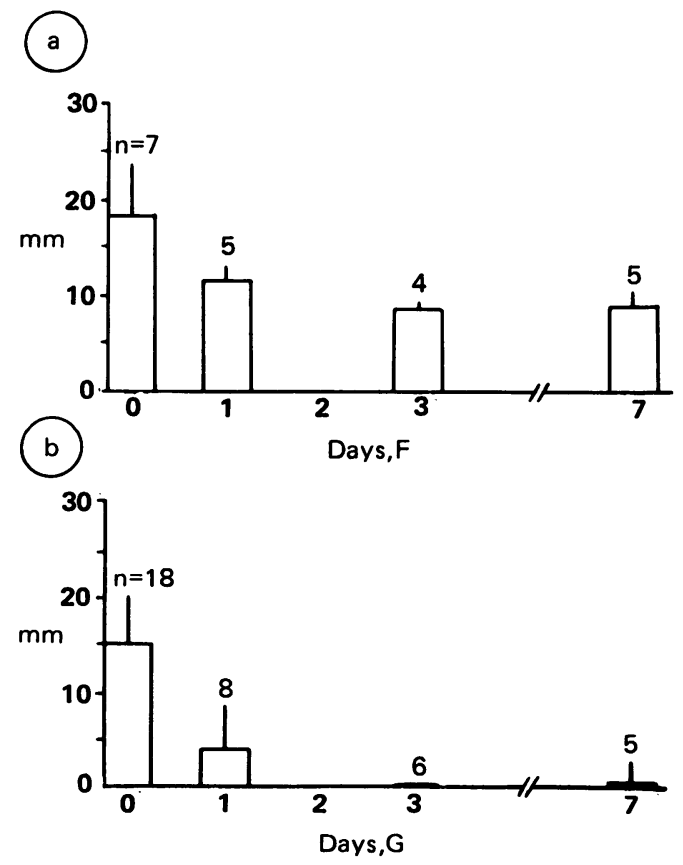

Fig 3 Time-course of elution of antibiotics from coating in vitro. (a) Diethanolamine fusidate-loaded $(F)$ coating. Tested after $0,1,3$ and 7 days of elution, (b) Gentamicinloaded $(G)$ coating. Tested after $0,1,3$ and 7 days of elution. sterilised by steam autoclave in theatre immediately before use.

Many patients with coated or uncoated implants received systemic antibiotics at the time of implantation or shortly thereafter, for one reason or another. At some centres this was routine, while at others (including the Maudsley Hospital) postoperative (not prophylactic) systemic antibiotics were given only if there was a specific indication. Of other centres implanting devices made to our designs, some used coated and some uncoated implants. Nearly all the surgeons were assisted in their first two implant operations by one of us (GSB).

\section{Results in vivo}

Crude infection rate and non-postoperative infections

Table 1 includes all devices designed in the MRC Neurological Prostheses Unit and implanted into patients up to March 31st, 1987, and includes all those that became infected. There were 21 of these, of which 16 had to be removed completely. In five it sufficed to remove the part that was known to be infected. Four of these five patients have now had the removed part replaced, and their implants are functioning.

In table 1 there is a statistically significant excess of infections in implants that had not been coated. Using Yates's correction for continuity, $\mathrm{X} 2=7 \cdot 5 ; 0.001<\mathrm{p}_{\mathbb{\mathrm { D }}}$ $<0.01$. However, this inclusive table does not yield $\frac{\rho}{\mathrm{O}}$ the best possible measure of the effectiveness of 0 coating, because there is reason to believe that 11 of the 21 infections were not introduced at the time of surgery, so that one would not expect the coating to be effective against them. Such a statement must be supported by clinical detail; the 11 are as follows:

(1) One patient with a coated cochlear prosthesis developed cerebrospinal otorrhoea on the 4th day after implantation. The leak was repaired surgically on the 10th day. Infection did not become evident until about the 30th day.

(2) One patient with a coated sacral anterior root stimulator began to leak CSF to the exterior from his operation wound about the 5th day after implantation. The leak persisted, and was repaired surgically on the 22nd day, using a patch of lyophilised dura in contact with the implant. At the time of repair there was no evidence of infection, but on the 25 th day pus was present.

(3) In one patient with a coated pain-relieving implant the wound dehisced as a result of accidental severe

Table 1 All implantations 1972-31 March 1987, and all infections

\begin{tabular}{llll}
\hline & Infection & No Infection & TOTAL \\
\hline Coated & 6 & 146 & 152 \\
Not coated & 15 & 90 & 105 \\
TOTAL & 21 & 236 & 257 \\
\hline
\end{tabular}


Table 2 Implantations and infections excluding infections that were probably not introduced at operation, and uninfected cases covered by the same exclusion rules (see text)

\begin{tabular}{lccc}
\hline & Infection & No Infection & TOTAL \\
\hline Coated & 1 & 142 & 143 \\
Not coated & 9 & 81 & 90 \\
TOTAL & 10 & 223 & 233 \\
\hline
\end{tabular}

trauma on the 10th postoperative day. It was resutured, but infection followed.

(4) In one patient with an uncoated intracranial pressure sensor there was no sign of infection, and the implant was working well, 7 months after implantation. At 16 months the scalp over it became infected, probably as a result of external injury. The implant was found to be infected later.

(5) In one patient with a coated penile drug delivery implant, the wound (which seemed uninfected) dehisced on the 10th postoperative day. It was re-sutured. From the 5th to the 14th week the implant was in use, and showed no sign of infection. From the 15 th to the 40th week it was not in use because of a mechanical failure, but still showed no sign of infection. In the 41st week it was explored surgically for the purpose of repair, and infection was found.

$(6,7,8)$ Of 10 uncoated semen-collecting implants put into men with spinal injuries, three became infected. Genital tract infection is so common in men with spinal injuries that it seems likely that these three infections arose from long-standing foci in the epididymis. Therefore the three infected implants and the seven comparable uninfected ones should be excluded.

$(9,10)$ Seven implantations were attempts to repair or replace an implant that had been partly (six cases) or wholly (one case) removed because of infection between 5 and 11 months previously. Among the six partial replacements, two (one coated, one uncoated) became infected, probably because of residues of the previous infection. We think that the two infected replacements and the five comparable uninfected ones (four coated, one uncoated) should be excluded.

(11) One uncoated artificial sphincter ulcerated through the urethra and became infected 12 months after implantation. It is likely that ulceration preceded infection.

\section{Rates of true postoperative implant infection}

Table 2 shows the implants remaining after making the above exclusions. The percentages of infections probably introduced at operation are $10.0 \%$ for uncoated implants and $0.7 \%$ for coated implants. This difference is highly significant (chi-square; $p<0.001$ ).

Table 3 shows the implants of table 2 classified by kind. Implants vary in size, surface-volume ratio, complexity of mechanism, and duration of the surgical procedure needed to implant them. The kinds are arranged in table 3 in rough order of total surface area. The order of duration of surgical procedure would be nearly the same, and these two variables seem likely to be positively correlated with the risk of infection at the time of operation. ${ }^{9}$ It can be seen that the distribution of implants between those of large and small surface area is roughly the same among coated and uncoated.

Table 4 shows the implants of table 2 classified by date. The distribution in time of coated and uncoated implants differs because coating was not introduced until 1982. However, the difference in numbers of coated and uncoated implants infected remains statistically significant, even if the 35 implants put in

Table 3 Implant numbers and infections classified by implant type

\begin{tabular}{|c|c|c|c|}
\hline Type of implant & $\begin{array}{l}\text { Number } \\
\text { coated } \\
\text { (infected) }\end{array}$ & $\begin{array}{l}\text { Number } \\
\text { uncoated } \\
\text { (infected) }\end{array}$ & $\operatorname{Ref}$ \\
\hline $\begin{array}{l}\text { Limb controller (both legs (6), one leg (2), or one hand (1)) } \\
\text { 3-channel sacral anterior root stimulator } \\
\text { Cerebellar stimulator } \\
\text { Conditional pudendal nerve stimulator } \\
\text { Visual prosthesis } \\
\text { Cochlear stimulator } \\
\text { Artificial urinary sphincter } \\
\text { Facial nerve stimulator } \\
\text { Hypogastric plexus stimulator } \\
\text { 1-channel extradural sacral root stimulator } \\
\text { Drug delivery implant (penis) } \\
\text { Peripheral nerve stimulator for pain relief } \\
\text { Vas deferens cannula and semen capsule (non-paraplegic patients) } \\
\text { Replacement of receiver (23), electrode (1) or pump (2) (pts not } \\
\text { previously infected) } \\
\text { Intracranial pressure sensor } \\
\text { Scrotal temperature sensor } \\
\text { Total }\end{array}$ & $\begin{array}{l}4(0) \\
104(1) \\
0 \\
3(0) \\
0 \\
1(0) \\
0 \\
1(0) \\
4(0) \\
3(0) \\
5(0) \\
0 \\
2(0) \\
16(0) \\
0 \\
0 \\
143(1)\end{array}$ & $\begin{array}{c}5(1) \\
40(2) \\
3(1) \\
1(1) \\
2(1) \\
0 \\
4(0) \\
0 \\
1(0) \\
0 \\
0 \\
1(0) \\
17(2) \\
10(1) \\
4(0) \\
2(0) \\
90(9)\end{array}$ & $\begin{array}{l}15,16 \\
14 \\
17 \\
18 \\
19 \\
- \\
\overline{18} \\
23 \\
- \\
- \\
20 \\
- \\
21 \\
22\end{array}$ \\
\hline
\end{tabular}


Table 4 Numbers of coated and uncoated implants classified by date of operation

\begin{tabular}{|c|c|c|c|c|}
\hline \multirow[b]{2}{*}{ Year } & \multicolumn{2}{|c|}{ Number not coated (number infected) } & \multicolumn{2}{|c|}{ Number coated (number infected) } \\
\hline & Maudsley & Other Centres & Maudsley & Other Centres \\
\hline $\begin{array}{l}1972 \\
1975 \\
1976 \\
1977 \\
1978 \\
1979 \\
1980 \\
1981 \\
1982 \\
1983 \\
1984 \\
1985 \\
1986 \\
1987 / J a n-M a r \\
\text { Total }\end{array}$ & $\begin{array}{l}1(0) \\
1(0) \\
2(0) \\
3(1) \\
7(0) \\
8(0) \\
7(0) \\
4(1) \\
3(1) \\
= \\
- \\
- \\
\overline{36}(3)\end{array}$ & $\begin{array}{l}\bar{E} \\
\bar{Z} \\
\overline{-} \\
\bar{Z} \\
\overline{2}(0) \\
1(1) \\
3(0) \\
9(0) \\
19(3) \\
17(2) \\
3(0) \\
54(6)\end{array}$ & $\begin{array}{l}\bar{Z} \\
\bar{Z} \\
\overline{-} \\
\overline{-} \\
\overline{-} \\
5(0) \\
9(0) \\
10(0) \\
8(0) \\
8(0) \\
5(0) \\
45(0)\end{array}$ & $\begin{array}{l}\bar{Z} \\
\bar{z} \\
\overline{-} \\
\overline{-} \\
\overline{-} \\
4(0) \\
11(0) \\
14(0) \\
25(0) \\
25(1) \\
19(0) \\
98(1)\end{array}$ \\
\hline
\end{tabular}

Table 5 Numbers of implants and infections classified by Centre

\begin{tabular}{|c|c|c|c|c|}
\hline Centre & $\begin{array}{l}\text { Systemic } \\
\text { Antibiotics }\end{array}$ & $\begin{array}{l}\text { Not coated } \\
\text { Implants } \\
\text { (infected) }\end{array}$ & $\begin{array}{l}\text { Coated } \\
\text { Implants } \\
\text { (infected) }\end{array}$ & $\begin{array}{l}\text { TOTAL } \\
\text { Implants } \\
\text { (infected) }\end{array}$ \\
\hline $\begin{array}{l}\text { Maudsley, London } \\
\text { Oxford/Sioke Mandeville } \\
\text { St Bartholomew's, London } \\
\text { Cardiff } \\
\text { Kings College Hospital, London } \\
\text { Sheffield } \\
\text { Edinburgh } \\
\text { Bad Wildungen } \\
\text { Christchurch NZ } \\
\text { Bad Haring } \\
\text { Guy's Hospital, London } \\
\text { Copenhagen } \\
\text { Maida Vale/Stanmore } \\
\text { Le Mans } \\
\text { The London Hospital } \\
\text { Stoke on Trent } \\
\text { 2 Centres (2 each) } \\
8 \text { Centres (1 each) } \\
\text { TOTAL }\end{array}$ & $\begin{array}{l}\mathbf{N} \\
\mathbf{N} \\
\mathbf{Y} \\
\mathbf{Y} \\
\mathbf{N} \\
\mathbf{Y} \\
\mathbf{Y} \\
\mathbf{Y}\end{array}$ & $\begin{array}{l}36(3) \\
0 \\
18(2) \\
12(2) \\
1(1) \\
6(0) \\
0(0) \\
0(0) \\
3(0) \\
4(0) \\
5(1) \\
3(0) \\
0(0) \\
0(0) \\
0(0) \\
1(0) \\
0(0) \\
1(0) \\
90(9)\end{array}$ & $\begin{array}{r}4(0) \\
26(0) \\
4(0) \\
2(0) \\
9(0) \\
4(0) \\
9(0) \\
9(0) \\
6(0) \\
3(0) \\
0(0) \\
2(0) \\
4(1) \\
4(0) \\
4(0) \\
2(0) \\
4(0) \\
7(0) \\
143(1)\end{array}$ & $\begin{aligned} & 80(3) \\
& 26(0) \\
& 22(2) \\
& 14(2) \\
& 10(1) \\
& 10(0) \\
& 9(0) \\
& 9(0) \\
& 9(0) \\
& 7(0) \\
& 5(1) \\
& 5(0) \\
& 4(1) \\
& 4(0) \\
& 4(0) \\
& 3(0) \\
& 4(0) \\
& 8(0) \\
& 233(10)\end{aligned}$ \\
\hline
\end{tabular}

during the period 1972-81 are discarded from the analysis.

\section{Effect of perioperative antibiotic prophylaxis on the rate of postoperative implant infection}

Table 5 shows the implants of table 2 classified by place of implantation, and also shows which centres are known to have a policy of perioperative systemic antibiotic prophylaxis in implant patients; the regimen varied between centres. Table 6 is derived from table 5 , and shows that for centres with a known policy of such treatment, $5 / 76$ implants $(6.6 \%)$ became infected; for those with no such policy, $4 / 116$ became infected (3.4\%). These rates are not significantly different, and the small excess of infections in patients with systemic prophylaxis is attributable to the larger proportion of uncoated implants in this group. When only the uncoated implants are considered (table 6, left), it is seen that the infection rate in patients with systemic prophylaxis was $4 / 40(10 \%)$, while for those without it was $4 / 37(10.8 \%)$. This difference is also insignificant, and a much larger series would be required in order to detect any slight benefit there may be from systemic prophylaxis.

\section{Discussion}

The results show that antibiotic-impregnated silicone rubber coating of stimulator implant cables and Table 6 Systemic prophylaxis and infections in coated and uncoated implants

\begin{tabular}{llll}
\hline $\begin{array}{l}\text { Systemic } \\
\text { prophylaxis } \\
\text { policy? }\end{array}$ & $\begin{array}{l}\text { Not Coated } \\
\text { (infected) }\end{array}$ & $\begin{array}{l}\text { Coated } \\
\text { (infected) }\end{array}$ & Total \\
\hline Yes & $40(4)$ & $36(1)$ & $76(5)$ \\
No & $37(4)$ & $79(0)$ & $116(4)$ \\
Total & $77(8)$ & $115(1)$ & $192(9)$ \\
\hline
\end{tabular}


receivers will probably greatly reduce the incidence of postoperative implant infection. The method described is simple, and can be used on any silicone rubber covered solid implant device, provided it is not allowed to get onto any part where surface finish or electrical or mechanical properties (for example plug-and-socket connectors) are important. Although formal safety evaluation has not been carried out, we have no evidence from any patient to suggest any hazard from implant coating using our method. The method may not be directly applicable to shunts, where many of the important infections occur on the luminal surface. ${ }^{3}$

The crucial period for implants not in permanent contact with the bloodstream is the first hours and perhaps days after surgery, ${ }^{10}$ and the crucial area to be protected is the fluid film around the implant. Some systemic antibiotics may reach this space but coating can surely achieve a much higher antibiotic concentration in it. This is reflected in the highly significant reduction in the rate of postoperative implant infections obtained using the coating method. No such reduction is seen in patients given systemic antibiotic prophylaxis instead of coating.

This work was supported by the Medical Research Council.

\section{References}

1 Bayston R, Lari J. A study of the sources of infection in colonised shunts. Dev Med Child Neurol. (Suppl.), 1974;32:16-32.

2 James HE. Infections associated with CSF prosthetic devices. In: Sugarman B, Young EJ, eds. Infections Associated with Prosthetic Devices. Boca Raton: CRC Press, 1984; 23-41.

3 Bayston R, Leung TSM, Wilkins BM, Hodges B. Bacteriological examination of removed cerebrospinal fluid shunts. $J$ Clin Pathol 1983;36:987-90.

4 Carlsson AS, Lidgren L, Lindberg L. Prophylactic antibiotics against early and late deep infections after total hip replacements. Acta Orthop Scand 1977;48:405-10.

5 Hill C, Flamant R, Mazas F, Everard J. Prophylactic cefazolin versus placebo in total hip replacement. Lancet 1981i:795-7.

6 Muers MF, Arnold AG, Sleight P. Prophylactic antibiotics for cardiac pacemaker implantation. A prospective trial. Br Heart J. 1981;43:539-44.

7 Pollard JP, Hughes SPF, Scott JE, Evans MJ, Benson MKD.
Antibiotic prophylaxis in total hip replacement. $\mathrm{Br} \mathrm{Med} J$ 1979;1:707-9.

8 Josefsson G, Lindberg L, Wiklander B. Systemic antibiotics and gentamicin-containing bone cement in the prophylaxis of postoperative infections in total hip arthroplasty. Clin Orthop 1981;159:194-200.

9 Haines SJ. Systemic antibiotic prophylaxis in neurological surgery. Neurosurgery 1980;6:355-61.

10 Hirschmann JV. Antibiotics in the prevention of infection associated with prosthetic devices. In: Sugarman B, Young EJ, eds. Infections Associated with Prosthetic Devices. Boca Raton: CRC Press, 1984; 269-78.

11 Bayston R, Milner RDG. Antimicrobial activity of silicone rubber uysed in hydrocephalus shunts, after impregnation with antimicrobial substances. J Clin Pathol. 1981;34:1057-62.

12 Donaldson PEK. Technology for implantable hermetic packages. 1. Design and materials. Med Biol Eng Comput. 1981;19: 398-402.

13 Donaldson PEK. The Cooper cable: an implantable multiconductor cable for neurological prostheses. Med Biol Eng Comput. 1983;21:371-4

14 Brindley GS, Polkey CE, Rushton DN, Cardozo L. Sacral anterior root stimulators for bladder control in paraplegia: the first 50 cases. J Neurol Neurosurg Psychiatry 1986;49:1104-14.

15 Brindley GS, Polkey CE, Rushton DN. Electrical splinting of the knee in paraplegia. Paraplegia 1978;16:428-35.

16 Donaldson N de N. Low-technology sealing method for inplantable hermetic packages. Med Biol Eng Comput 1988;26:111-6.

17 Brindley GS, Fenton GW, Fenwick PBC, Polkey CE, Rushton DN. Visual evoked potentials from implanted cerebellar electrodes. Electroencephalogr Clin Neurophysiol 1978;44:792-3.

18 Brindley GS, Donaldson PEK. Electrolytic current-control elements for surgically implanted electrical devices. Med Biol Eng Comput 1986;24:439-41.

19 Rushton DN, Brindley GS. Short- and long-term stability of cortical electrical phosphenes. In: Rose FC, ed. Physiological Aspects of Clinical Neurology. Oxford: Blackwell, 1977; 123-53. 20 Brindley GS, Scott GI, Hendry WF. Vas cannulation with implanted sperm reservoirs for obstructive azoospermia or ejaculatory failure. $\mathrm{Br} J$ Urol 1986;58:721-3.

21 Brindley GS, Polkey CE, Cooper JD. Technique for very longterm monitoring of intracranial pressure. Med Biol Eng Comput. 1983;21:460-4.

22 Brindley GS, Cooper JD. Deep scrotal temperature and the effects on it of clothing, air temperature, activity, posture and paraplegia. Br J Urol. 1982;54:49-55.

23 Brindley GS. Sacral root and hypogastric stimulators and what these implants tell us about autonomic actions on the bladder and urethra. Clin Sci. 1986;70 (Suppl. 14):41s-44s.

24 Brindley GS, Polkey CE, Rushton DN. Sacral anterior nerve root stimulators: notes for surgeons and physicians. Welwyn Garden City: UK. Finetech, 1988. 